\title{
Risk factors predicting graft-versus-host disease and relapse-free survival after allogeneic hematopoietic stem cell transplantation in relapsed or refractory non-Hodgkin's lymphoma
}

\author{
Young-Woo Jeon ${ }^{1,2,3,4} \cdot$ Seugyun Yoon ${ }^{1,2} \cdot$ Gi June Min ${ }^{1,2} \cdot$ Sung-Soo Park ${ }^{1,2} \cdot$ Silvia Park ${ }^{1,2} \cdot$ Jae-Ho Yoon ${ }^{1,2}$. \\ Sung-Eun Lee ${ }^{1,2} \cdot$ Byung-Sik Cho ${ }^{1,2} \cdot \mathrm{Ki}^{1, S e o n g ~ E o m ~}{ }^{1,2} \cdot$ Yoo-Jin Kim ${ }^{1,2} \cdot$ Hee-Je Kim ${ }^{1,2} \cdot$ Seok Lee ${ }^{1,2} \cdot$ Chang-Ki Min $^{1,2}$. \\ Jong Wook Lee ${ }^{1,2} \cdot$ Seok-Goo Cho ${ }^{1,3,4}$
}

Received: 19 November 2018 / Accepted: 6 May 2019 / Published online: 14 May 2019

(C) The Author(s) 2019

\begin{abstract}
Allogeneic hematopoietic stem cell transplantation (allo-HSCT) is still considered a definitive curative modality for refractory or relapsed non-Hodgkin's lymphoma (NHL). However, transplant-related morbidity and mortality remain a considerable challenge. The graft-versus-host disease (GVHD)-free with relapse-free survival (GRFS) rate and GRFS-related prognostic factors have not been fully examined for NHL alone. We evaluated 104 consecutive patients with refractory or relapsed aggressive NHL receiving alloHSCT at a single institution. With a median follow-up of 31.5 months, the estimated 3-year overall survival (OS), disease-free survival (DFS), the cumulative incidence rates of relapse, and non-relapse mortality were $45.9 \%, 45.9 \%, 36.0 \%$, and $17.0 \%$, respectively. The patients with overall grades III-IV acute GVHD had markedly inferior OS and DFS ( $p=0.040$ for OS and $p=0.028$ for DFS). However, patients with more than mild stage chronic GVHD showed superior OS and DFS ( $p=0.004$ and $p=0.008$, respectively). The 1- and 3-year GRFS rates were $44.5 \%$ and $36.9 \%$, respectively. The negative bone marrow involvement at diagnosis, chemosensitive disease status, and fewer exposure lines of chemotherapy before transplantation significantly increased the GRFS incidence. However, no transplant-associated factors were related to GRFS incidence. Furthermore, applying dynamic GRFS method which excepted patients whose chronic GVHD was fully resolved within short-period, survival rate significantly increased over time ( $36.9 \%$ vs. $41.9 \%, p=0.045$ for conventional GRFS vs. dynamic GRFS at 3 years after transplantation). In conclusion, these results suggest that GRFS is also a useful endpoint to assess transplant outcomes, and the dynamic GRFS calculation, including rapidly manageable chronic GVHD, is a more practical method for patients with refractory or relapsed heterogenous subtypes of NHL.
\end{abstract}

Keywords Allogeneic hematopoietic stem cell transplantation · Endpoint · Graft-versus-host disease $\cdot$ Lymphoma

Electronic supplementary material The online version of this article (https://doi.org/10.1007/s00277-019-03714-x) contains supplementary material, which is available to authorized users.

Seok-Goo Cho

chosg@ catholic.ac.kr

1 Division of Lymphoma-Myeloma, Catholic Hematology Hospital, Seoul St. Mary's Hospital, College of Medicine, The Catholic University of Korea, \#505, Banpo-Dong, Seocho-Ku, Seoul 06591, Republic of Korea

2 Leukemia Research Institute, College of Medicine, The Catholic University of Korea, Seoul, Republic of Korea

3 Institute for Translational Research and Molecular Imaging, Catholic Institutes of Medical Science, Seoul, Republic of Korea

4 Laboratory of Immune Regulation, Convergent Research Consortium for Immunologic Disease, Seoul St. Mary's Hospital, Seoul, Republic of Korea

\section{Introduction}

Since rituximab-based chemoimmunotherapy and several novel targeted therapies were introduced, the survival outcomes of patients on the spectrum of non-Hodgkin's lymphoma (NHL), from indolent to aggressive subtypes, have improved drastically $[1,2]$. However, approximately half of patients with advanced NHL fail to achieve a complete response (CR), and numerous salvage treatments with concomitant novel agents or autologous hematopoietic stem cell transplantation (auto-HSCT) have been applied to overcome these obstacles depending on the patient's clinicopathological condition. However, final survival outcomes have been disappointing [3-5].

In this circumstance, allogeneic hematopoietic stem cell transplantation (allo-HSCT) is considered a 
potentially curative option in patients experiencing relapse after auto-HSCT, and in those who are chemorefractory after multiple chemotherapy regimens [6]. As allo-HSCT procedures have evolved over the years according to changes in conditioning intensity and alternative donor selection, 5-year overall survival (OS) and progressionfree survival (PFS) rates have reached $30-65 \%$ and $37-$ $60 \%$, respectively [6-8]. Survival outcome was thought to be predicated on the use of tumor-free grafts, as well as a potential allogeneic effect exerted by donor $\mathrm{T}$ cells, known as the graft-versus-lymphoma (GVL) effect. However, adverse events, such as transplant-related complications and disease recurrence, are the most troublesome [9]; acute graft-versus-host disease (GVHD) or chronic GVHD is related to poor non-relapse mortality (NRM) and decreased the quality of life (QoL). Disease recurrence after allo-HSCT and transplant-related mortality (TRM) have failed to maintain satisfactory allo-HSCT OS and DFS rates [9].

Most clinical studies on allo-HSCT have focused primarily on OS or DFS and have only evaluated the effectiveness of the transplantation itself. However, a major drawback in this kind of analysis is that these studies dealt separately with transplant-related complications, which significantly decrease QoL, such as severe acute GVHD and extensive chronic GVHD, and may not reflect the ultimate efficacy of allo-HSCT. Thus, there is a need to appropriately evaluate the objective effectiveness of allo-HSCT and the subjective improvement in the patient's experience. To compensate for this pitfall, Holtan et al. proposed that the novel composite endpoint of GVHD-free relapse-free survival (GRFS) after HSCT be defined as survival without grades III-IV acute GVHD, moderate to severe chronic GVHD requiring systemic immunosuppressive therapy, relapse, or death $[10,11]$. GRFS is now widely used to measure the success of HSCT in many hematological malignancies, such as acute leukemia and myelodysplastic syndrome, but research on NHL-specific GRFS is relatively limited because NHL is not a disease considered to be upfront for allo-HSCT at the initial diagnosis. Thus, candidates with NHL for alloHSCT are inevitably exposed to multiple lines of chemotherapy in a chemosensitive or chemorefractory relapse pattern, in addition to a reduced intensity conditioning (RIC) regimen.

Therefore, it is essential to understand the equivalent survival outcomes between post-HSCT disease relapse and transplant-related GVHD for relapsed or refractory patients with NHL. We identified the GRFS rate as an effective modality influencing practical survival outcomes in patients with NHL alone and examined the GRFSassociated prognostic factors for patients with faradvanced NHL alone.

\section{Materials and methods}

\section{Study design}

Adult patients who underwent allo-HSCT for relapsed or refractory lymphoma from January 2008 to January 2017 at our institute were screened, and subjects who were diagnosed pathologically with NHL were selected for the analysis. The observations were extended until April 2018 to ensure a minimum follow-up duration of 12 months. Clinical data were retrospectively extracted from the patient's electronic medical records, including demographic information, initial or salvage chemotherapy, response to initial or salvage chemotherapy, high dose chemotherapy followed by autologous stem cell rescue, disease status at allo-HSCT, and outcome. We treated 104 relapsed or refractory consecutive patients with RIC regimens or myeloablative conditioning (MAC) regimens after several salvage chemotherapies. Experienced lymphoma pathologists confirmed the pathology according to the 2008 World Health Organization classification [12].

\section{Human leukocyte antigen typing}

Human leukocyte antigen (HLA) typing for HLA-A, HLA-B, HAL-C, and HLA-DR was performed on all patients and donors to ensure appropriate matches; "well matched" was defined as non-disparity between the donor and recipient at HLA-A, B, C, and DR1 (8/8), "partially matched" was a single known or likely disparity, "mismatched" was two or more disparities, and haploidentical donors were those with a 6-4/8 HLA matching degree [13]. Sibling or unrelated donors were classified according to donor type.

\section{Conditioning regimen and prophylaxis for graft-versus-host disease}

The MAC regimen consisted of cyclophosphamide $(120 \mathrm{mg} / \mathrm{kg}$ ) and $30 \mathrm{mg} / \mathrm{kg}$ etoposide in combination with total body irradiation (TBI; $1200 \mathrm{cGy}$ in four fractionated doses over 4 days). RIC mainly included $30 \mathrm{mg} / \mathrm{m}^{2}$ fludarabine for 6 consecutive days (total, $180 \mathrm{mg} / \mathrm{m}^{2}$ ) plus $70 \mathrm{mg} / \mathrm{m}^{2}$ melphalan for 1 day with additional TBI of $800 \mathrm{cGy}$ in four fractionated doses for 2 days (FMT regimen). Another RIC regimen was $30 \mathrm{mg} / \mathrm{m}^{2}$ fludarabine for 6 consecutive days (total, $180 \mathrm{mg} / \mathrm{m}^{2}$ ) plus $1.6 \mathrm{mg} / \mathrm{kg}$ busulfan for 2 days (total, $3.2 \mathrm{mg} / \mathrm{kg}$ ) with $800 \mathrm{cGy}$ TBI for 2 days. Antithymocyte globulin (rabbit ATG, $2.5-5.0 \mathrm{mg} / \mathrm{kg}$; Genzyme Transplant, Cambridge, MA, USA) was administered as part of the conditioning regimen for some patients treated with RIC, $1.25 \mathrm{mg} / \mathrm{kg}$ for 2 days (total, $2.5 \mathrm{mg} / \mathrm{kg}$ ) in patients receiving from one allele mismatched to one antigen mismatched donor, and $2.5 \mathrm{mg} / \mathrm{kg}$ for 2 days in patients with a haploidentical donor regardless of whether it was a sibling or 
unrelated. Moreover, GVHD prophylaxis mainly consisted of a calcineurin inhibitor (cyclosporine for all sibling transplants and tacrolimus for unrelated transplants or haploidentical transplants) with a short course of methotrexate $\left(5 \mathrm{mg} / \mathrm{m}^{2}\right.$ for tacrolimus and $10 \mathrm{mg} / \mathrm{m}^{2}$ for cyclosporine) on days +1 , $+3,+6$, and +11 during the transplant period. There was no post-transplant cyclophosphamide (PT-CY)-based GVHD prophylaxis strategy in our cohort. The MAC regimen was selected for younger patients with good general health status in addition to CR disease status before strict allo-HSCT. Patients who did not meet the conditions for MAC were treated with RIC, and haploidentical transplants were adopted with the same RIC method. All patients were managed in a specific sterilized room with laminar airflow and high-efficacy air purification filters. Acyclovir and itraconazole were prescribed to all patients for viral and fungal prophylaxis. All patients received granulocyte-colony stimulating factor (filgrastim) beginning on the day when the absolute neutrophil count (ANC) was $<0.5 \times 10^{9}$ cells $/ \mathrm{L}$ at a dose of $5 \mu \mathrm{g} / \mathrm{kg} /$ day subcutaneously until the ANC was $>1.0 \times 10^{9}$ cells/L. Other conservative management was performed according to the event.

\section{Clinical survival outcomes and evaluation of transplant-related risks}

The primary outcomes were 1- and 3-year GRFS for patients with NHL alone, and current GRFS was evaluated as the composite in the absence of grades III-IV acute GVHD, systemic immunosuppressive therapy-requiring chronic GVHD, relapse, or death from any cause, during each time point after allo-HSCT [10]. The prognostic parameters for GRFS were assessed at 1 and 3 years after allo-HSCT. If multiple GRFSrelated events occurred in one patient, the first post-transplant event was recognized within 1 and 3 years. Secondary outcomes evaluated OS and PFS, the cumulative incidence of GRFS-related acute or chronic GVHD, relapse, and NRM. Additionally, transplant-related risk was calculated by the European Group for Blood and Marrow Transplantation (EBMT) scoring system, including age at diagnosis and HSCT, pre-HSCT status, and donor-recipient combinations [14]. Chemotherapy-related toxicity was calculated using the National Cancer Institute Common Toxicity Criteria for Adverse Events (ver. 4.0), and acute GVHD and chronic GVHD were diagnosed and graded according to the system of Glucksberg/Thomas and the National Institutes of Health Consensus $[15,16]$.

\section{Statistical analysis}

Surviving patients were censored on the last day of follow-up. All GRFS-associated categorical variables are expressed as proportions and compared with the chi-square or Fisher's exact test, and continuous variables are presented as median with range and compared using the Mann-Whitney $U$ test between the two groups. OS, DFS, and GRFS rates were calculated using the Kaplan-Meier survival method in a log-rank analysis. Cumulative incidence estimates of acute GVHD, chronic GVHD, relapse, and NRM were calculated with relapse or death from other causes defined as competitive events, using the Gray test for univariate analysis and the Fine-Gray method for the proportional hazard regression. All statistical analyses were performed using $\mathrm{R}$ software (ver. 3.2.0; Comprehensive R Archive Network project, http://cran.us.rproject.org) with the EZR graphical user interface of Y. Kanda (Saitama Medical Center, Jichi Medical University, Saitama, Japan) [17].

\section{Results}

\section{Patient characteristics}

The baseline clinical characteristics of the 104 patients included in the study are summarized in Table 1 . The median ages at the initial diagnosis and allo-HSCT of the entire cohort were 39 (range 18-64 years) and 40 years (range 19-65 years), respectively. Moreover, the proportion of male patients was higher $(n=68,65.4 \%)$. The pathological phenotype distribution was 50 patients $(48.1 \%$ ) with B cell NHL and 54 patients (51.9\%) with T cell NHL, and specific subtypes of B cell and $\mathrm{T}$ cell NHL were also shown in Table 1 . The majority of patients presented with advanced disease status at the initial diagnosis, Ann Arbor stage IV ( $n=59,56.7 \%)$, elevated serum lactate dehydrogenase $(n=67,64.4 \%)$, involvement of two or more lymph nodes $(n=67,64.4 \%)$, and bone marrow (BM) involvement ( $n=46,44.2 \%)$. Eighty-eight patients $(84.6 \%)$ had a relatively favorable Eastern Oncology Group performance score of $0-1$. The mean number of systemic chemotherapy regimens before allo-HSCT was four. Moreover, $11(10.6 \%)$ patients were treated with five or more rounds of chemotherapy, and 38 patients $(36.5 \%)$ developed progressive disease after an autologous stem cell transplant. Accordingly, the interval from the initial diagnosis to transplant was > 12 months $(n=72,69.2 \%)$. Only 35 patients $(33.7 \%)$ had CR status before allo-HSCT, and 26 patients $(25 \%)$ had PR; in other words, fewer than half of all patients were in a relapsed or refractory state after final salvage chemotherapy preHSCT (43 patients with SD or PD, 41.3\%).

\section{Transplantation-related characteristics}

The transplant-associated characteristics are given in Table 2. Peripheral blood was the source of stem cells for most patients $(n=99,95.3 \%)$. The majority of patients were treated with the FMT conditioning regimen: 76 patients $(73.1 \%)$ received the FMT conditioning regimen, 19 patients $(18.3 \%)$ received the 
Table 1 Patient characteristics

\begin{tabular}{|c|c|}
\hline Factors & $N=104(\%)$ \\
\hline Age, year, median (range) at initial diagnosis & $39(18-64)$ \\
\hline Gender, male (\%) & $68(65.4)$ \\
\hline \multicolumn{2}{|l|}{ Pathological subtype (\%) } \\
\hline Diffuse large B cell lymphoma & $30(28.8)$ \\
\hline T cell lymphoblastic lymphoma & $17(16.4)$ \\
\hline Peripheral T cell lymphoma, NOS & $13(12.5)$ \\
\hline Extranodal NK/T cell lymphoma-nasal type & $9(8.7)$ \\
\hline B cell lymphoblastic lymphoma & $8(7.7)$ \\
\hline Mantle cell lymphoma & $6(5.8)$ \\
\hline Angioimmunoblastic T cell lymphoma & $6(5.8)$ \\
\hline Aggressive NK cell lymphoma & $6(5.8)$ \\
\hline Follicular lymphoma & $2(1.9)$ \\
\hline Plasmablastic lymphoma & $2(1.9)$ \\
\hline Others ${ }^{\star}$ & $5(4.7)$ \\
\hline \multicolumn{2}{|c|}{ International Prognostic Index (IPI) at initial diagnosis } \\
\hline Low & $33(31.7)$ \\
\hline Low-intermediate & $32(30.8)$ \\
\hline High-intermediate & $27(26.0)$ \\
\hline High & $12(11.5)$ \\
\hline \multicolumn{2}{|l|}{ Ann Arbor stage at initial diagnosis } \\
\hline I & $2(1.9)$ \\
\hline II & $25(24.0)$ \\
\hline III & $18(17.3)$ \\
\hline IV & $59(56.7)$ \\
\hline \multicolumn{2}{|l|}{ LDH at initial diagnosis } \\
\hline Normal & $44(42.3)$ \\
\hline Elevated (> $450 \mathrm{IU} / \mathrm{L})$ & $60(57.7)$ \\
\hline Extranodal lymph node involvement $(\geq 2)$ & $67(64.4)$ \\
\hline \multicolumn{2}{|l|}{ ECOG PS at initial diagnosis } \\
\hline $0-1$ & $88(84.6)$ \\
\hline$\geq 2$ & $16(15.4)$ \\
\hline Bone marrow involvement at initial diagnosis & $46(44.2)$ \\
\hline Bone marrow involvement before allo-HSCT & $13(12.5 \%)$ \\
\hline \multicolumn{2}{|l|}{ Beta2-microglobulin } \\
\hline Normal & $44(42.3)$ \\
\hline Elevated $(\geq 2.5 \mathrm{mg} / \mathrm{L})$ & $37(35.6)$ \\
\hline Not assessed & $23(22.1)$ \\
\hline History of prior auto-HSCT & $38(36.5)$ \\
\hline no & $66(63.5)$ \\
\hline yes & $38(36.5)$ \\
\hline \multicolumn{2}{|l|}{ Lines of chemotherapy before allo-HSCT } \\
\hline 1 & $1(1.0)$ \\
\hline 2 & $24(23.0)$ \\
\hline 3 & $26(25)$ \\
\hline 4 & $42(40.4)$ \\
\hline$\geq 5$ & $11(10.6)$ \\
\hline \multicolumn{2}{|l|}{ Disease status at allo-HSCT } \\
\hline $\mathrm{CR}$ & $35(33.7)$ \\
\hline PR & $26(25)$ \\
\hline $\mathrm{SD} / \mathrm{PD}$ & $43(41.3)$ \\
\hline \multicolumn{2}{|l|}{ Interval period from diagnosis to transplant } \\
\hline$<12$ months & $32(30.8)$ \\
\hline $12-24$ months & $28(26.9)$ \\
\hline$>24$ months & $44(42.3)$ \\
\hline
\end{tabular}

*Others: anaplastic large cell lymphoma, chronic lymphocytic leukemia, enteropathy-associated T cell lymphoma, hepatosplenic T cell lymphoma, and subcutaneous panniculitis T cell lymphoma

$N O S$, not otherwise specified; $N K$, natural killer; $L D H$, lactate dehydrogenase; $E C O G$, Eastern Cooperative Oncology Group performance status; $H S C T$, hematopoietic stem cell transplantation; $C R$, complete response; $P R$, partial response; $S D$, stable disease; $P D$, progressive disease
Table 2 Allogeneic stem cell transplantation-related characteristics

\begin{tabular}{|c|c|}
\hline Factors & $N=104(\%)$ \\
\hline \multicolumn{2}{|l|}{ HCT-CI (score) } \\
\hline 0 & $35(33.7)$ \\
\hline $1-2$ & $41(39.4)$ \\
\hline$\geq 3$ & $28(26.9)$ \\
\hline \multicolumn{2}{|l|}{ Conditioning regimen } \\
\hline RIC $1(\mathrm{Flu}+\mathrm{Mel}+\mathrm{TBI})$ & $76(73.1)$ \\
\hline RIC $2(\mathrm{Flu}+\mathrm{Bu})$ & $19(18.3)$ \\
\hline $\mathrm{MAC}(\mathrm{Cy}+\mathrm{Eto}+\mathrm{TBI})$ & $9(8.6)$ \\
\hline \multicolumn{2}{|l|}{ Use of ATG } \\
\hline No & $62(59.6)$ \\
\hline Yes & $42(40.4)$ \\
\hline \multicolumn{2}{|l|}{ Donor type } \\
\hline Matched related & $34(32.7)$ \\
\hline Mismatched related & 0 \\
\hline Matched unrelated & $35(33.2)$ \\
\hline Mismatched unrelated & $13(12.5)$ \\
\hline Haploidentical donor & $22(21.6)$ \\
\hline \multicolumn{2}{|l|}{$\mathrm{ABO}$ matching degree } \\
\hline Fully matched & $50(48.1)$ \\
\hline Minor mismatched & $18(17.3)$ \\
\hline Major mismatched & $36(34.6)$ \\
\hline \multicolumn{2}{|l|}{ Stem cell source } \\
\hline Peripheral blood & $99(95.2)$ \\
\hline Bone marrow & $5(4.8)$ \\
\hline
\end{tabular}

HCT-CI, Hematopoietic Cell Transplant-specific Comorbidity Index; $R I C$, reduced intensity conditioning; $M A C$, myeloablative conditioning; $A T G$, anti-thymoglobulin; Flu, fludarabine; Mel, melphalan; TBI, total body irradiation; Eto, etoposide

fludarabine-busulfan regimen, and $9(8.6 \%)$ were transplanted with the MAC regimen. Fewer than half of all patients $(n=42$, 40.4\%) were treated with ATG as part of their conditioning regimen. Donors for 34 patients (32.7\%) were HLA-identical siblings, 35 patients $(33.2 \%)$ were transplanted with HLAidentical unrelated, and a considerable number of patients $(n=$ $22,21.6 \%$ ) were infused with HLA-haploidentical stem cells.

\section{Hematological recovery and engraftment}

All patients were evaluable for hematopoietic recovery and chimerism status. Patients received a median of $7.98 \times 10^{6}$ CD34+ cells $/ \mathrm{kg}$ (range $2.91 \times 10^{6}-16.98 \times 10^{6} \mathrm{CD} 34+$ cell $/ \mathrm{kg}$ ). After stem cell transplantation, engraftment was achieved at a median of 13.3 days for an $\mathrm{ANC} \geq 500 / \mu \mathrm{L}$ and 15.2 days for platelet recovery $(\geq 50,000 / \mu \mathrm{L}$ for 3 consecutive days without transfusion). All patients who underwent alloHSCT had donor chimerism according to peripheral blood and showed chimerism data $>97 \%$ at 30 days post- 
transplant; full-donor chimeras were successfully completed in all patients.

\section{Survival outcomes after allo-HSCT}

CR was observed in 68 patients $(65.4 \%)$ after allo-HSCT. Among them, 23 patients $(33.8 \%)$ had a pre-transplant disease status of refractory or relapsed to salvage chemotherapy or auto-HSCT. The median follow-up duration was 31.5 months (range 11.5-13.56 months) in surviving patients, and the median interval from the initial diagnosis to allo-HSCT in all patients was 19.8 months (range 5.6-86.2 months). The 1year OS and DFS rates were $64.8 \%$ (95\% confidence interval (CI) 54.7-73.2) and 64.7\% (95\% CI 54.7-73.0), respectively. The cumulative incidence rates of relapse and NRM at 1 year were $20.5 \%$ (95\% CI $13.3-28.9$ ) and $12.5 \%$ (95\% CI 6.4 20.8), respectively (Fig. 1). The 3-year OS and DFS rates were
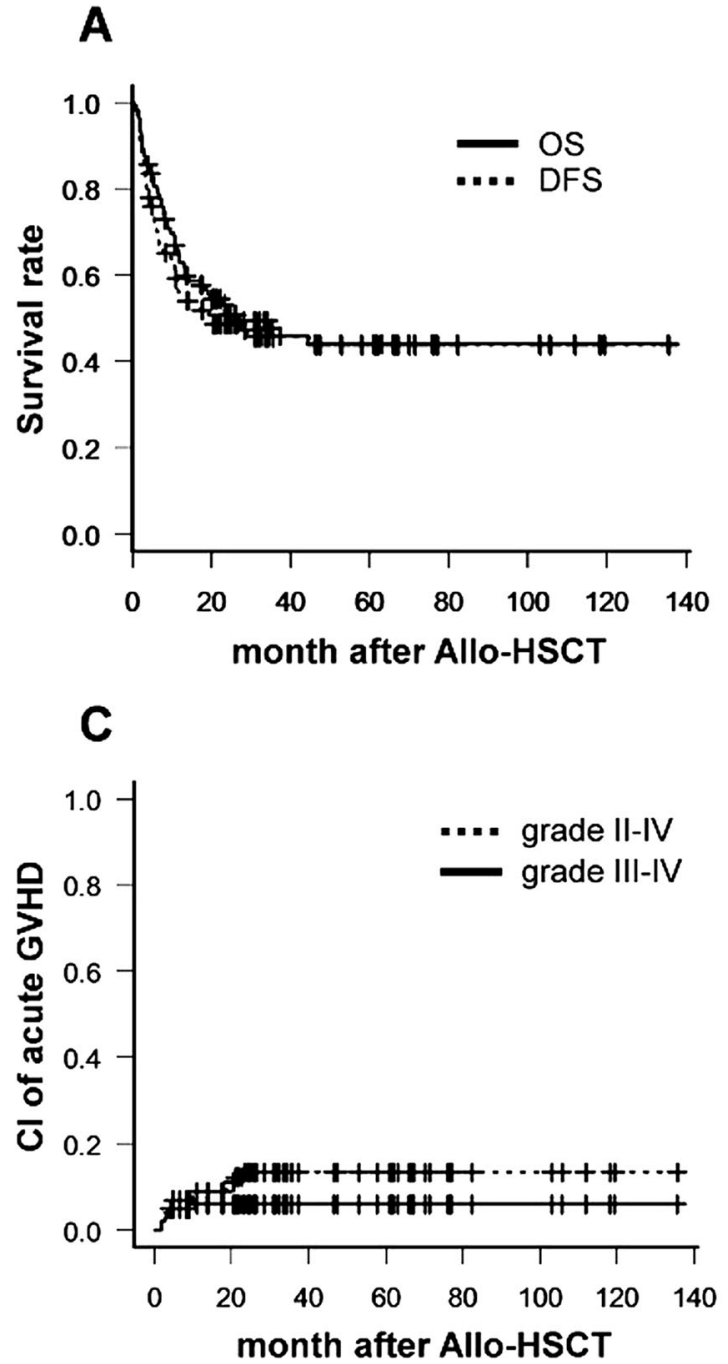

Fig. 1 Survival outcome and GVHD incidence after allogeneic hematopoietic stem cell transplantation. a Overall survival and diseasefree survival. b Cumulative incidence of relapse and non-relapse
$45.9 \%$ (95\% CI 35.2-55.9) and $45.9 \%$ (95\% CI 35.2-54.3), respectively. The cumulative incidence rates of relapse and NRM at 3 years were 36.0 (95\% CI 26.1-46.0) and $17.0 \%$ (95\% CI 9.5-26.5), respectively (Fig. 1).

\section{Graft-versus-host disease after allo-HSCT}

Any grade of acute GVHD occurred in 37 (35.6\%) patients. Acute GVHD grades II-III was identified in $13(12.5 \%)$ and 6 (5.8\%) patients, respectively. Any stage of chronic GVHD was seen in 58 patients $(55.8 \%)$. Furthermore, moderate and chronic stage GVHDs were identified in $14(13.5 \%)$ and 6 (5.8\%) patients, respectively (Fig. 1). Figure 2 panel a shows that patients with overall grades III-IV of acute GVHD had the markedly inferior OS and DFS than the group with overall grades I-II acute GVHD or no acute GVHD ( $p=0.040$ for OS and $p=0.028$ for DFS, respectively). However, patients with
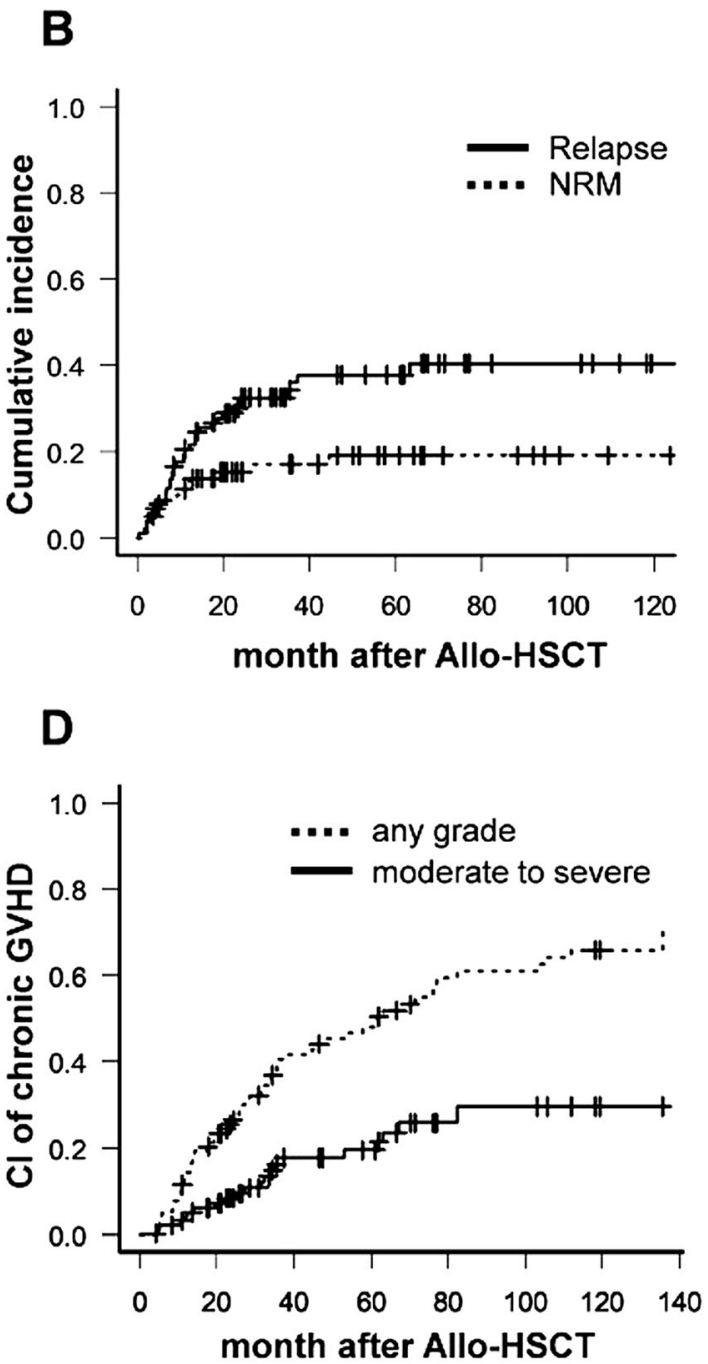

mortality. c Cumulative incidence of acute graft-versus-host disease (GVHD). d Represents chronic GVHD according to each severity 

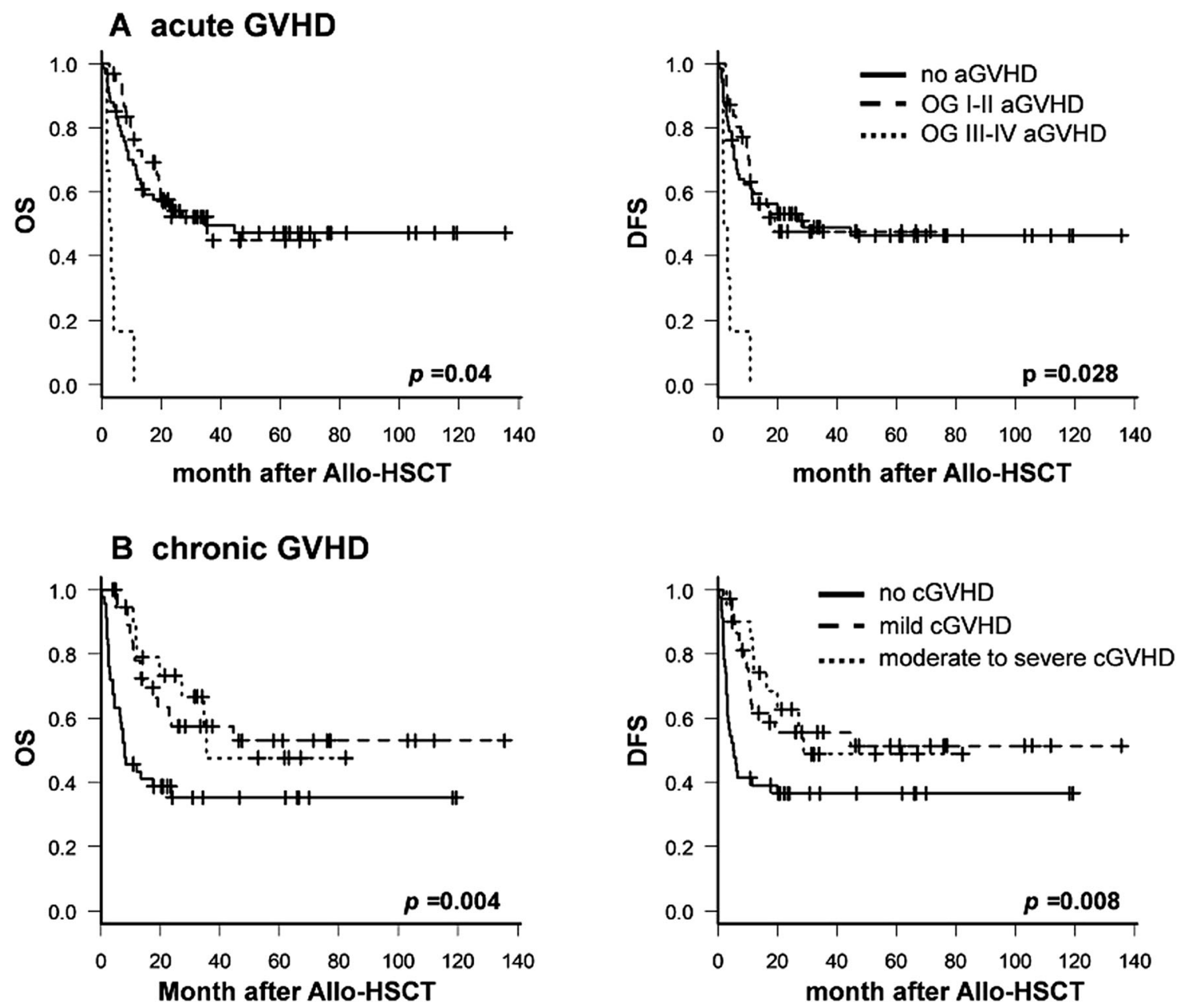

Fig. 2 Survival outcomes according to acute GVHD and chronic GVHD. a Overall survival (OS) and disease-free survival (DFS) according to a grade of acute graft-versus-host disease (GVHD). b OS and DFS according to the severity of chronic GVHD

more than mild stage chronic GVHD showed superior OS and DFS ( $p=0.004$ and 0.008 , respectively) (Fig. 2 panel b). Furthermore, more than moderate stage chronic GVHD was still superior in terms of OS compared with non-chronic GVHD, and DFS did not differ in patients with non-chronic GVHD (Fig. 2 panel b).

\section{Clinical factors associated with GRFS}

The GRFS rate at 1 year after allo-HSCT was $44.5 \%$ (95\% CI 34.7-53.8) in the entire cohort, and all comparisons with OS (64.8\%; 95\% CI 54.7-73.2) and DFS (64.7\%; 95\% CI 54.773.0) during the same period are shown in Supplementary Figure 1. Also, the 3-year GRFS rate was $36.9 \%$ (95\% CI 27.5-46.3) compared with an OS of $45.9 \%$ (95\% CI $35.2-$ 55.9) and DFS of 45.9\% (95\% CI 35.2-54.3) (Supplementary Figure 1). The comparative analysis of GRFS and clinical factors was performed by classifying the factors related to the disease characteristics and the factors related to the transplant features. In the analysis of lymphoma-specific characteristics factors, 3-year GFRS was significantly favorable in patients with $\leq 3$ lines of chemotherapy before alloHSCT ( $47 \%$ vs. $27 \%, p=0.018$ ), no BM involvement at the initial diagnosis (50\% vs. $27 \%, p=0.033$ ), and chemosensitive disease status before transplant (48\% vs. $21 \%, p=0.018$ ) (Fig. 3 panel a). However, there were no major modifiable transplant-associated factors which correlated with the 3-year GRFS incidence, including of HLA matching degree ( $40 \%$ vs. $15 \%$ in HLA well or partially matched vs. mismatched, $p=0.077$ ), use of ATG ( $42 \%$ vs. $34 \%$ in with ATG vs. without ATG, $p=0.370$ ), conditioning intensity ( $65 \%$ vs. $35 \%$ in MAC vs. RIC, $p=0.179)$, the Hematopoietic Cell Transplant-specific Comorbidity Index (HCT-CI), donor type (sibling or unrelated), and stem cell source (BM or peripheral blood) (Fig. 3 panel b).

\section{Causes of GRFS events}

To investigate whether the distribution of GRFS-defining events was due to the incidence of relapse or the GVHD 


\section{A Disease characteristic factors}
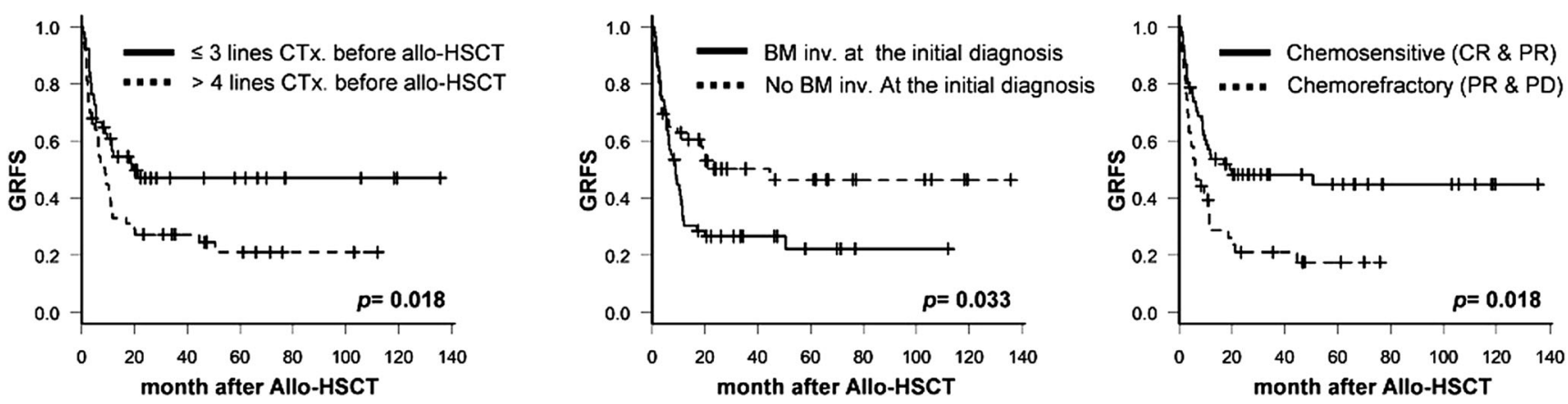

\section{B Transplant-associated factors}

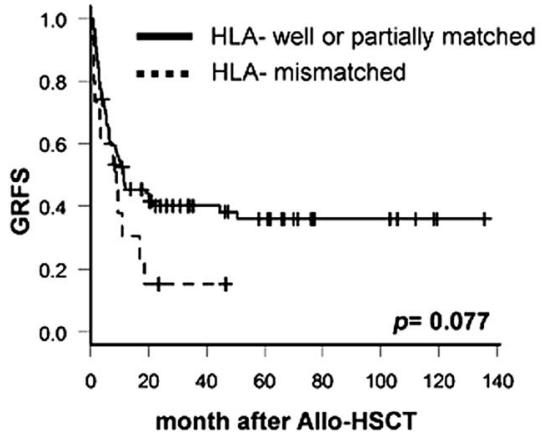

Fig. 3 Clinical factors influencing GVHD-free with relapse-free survival (GRFS). a Disease characteristic factors associated with GRFS; GRFS differed according to cumulative lines of chemotherapy before alloHSCT, bone marrow involvement at diagnosis, and disease status prior
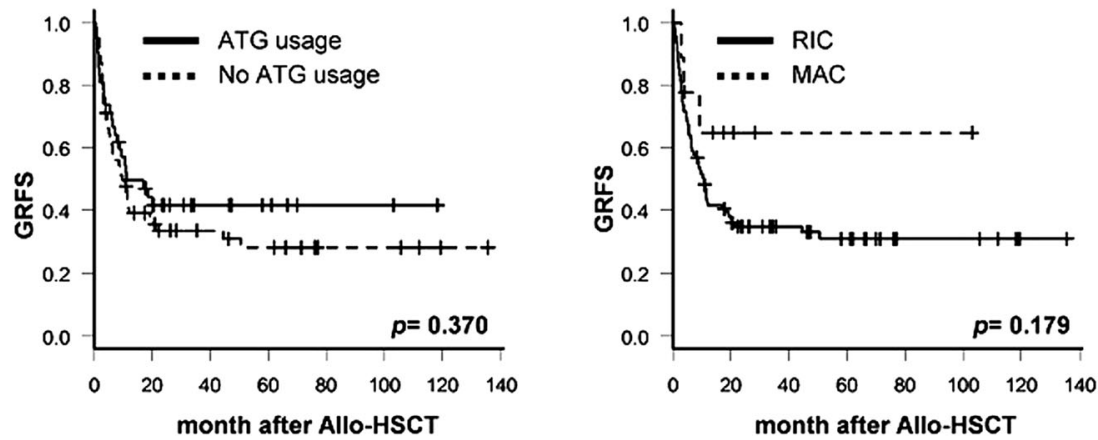

to allo-HSCT. b Shows that transplant-associated factors influencing GRFS; GFRS differed according to HLA matching degree, usage of anti-thymocyte globulin, and conditioning intensity

the novel concept of GRFS to avoid possible confounding factors due to various clinical presentations and therapeutic approaches for other hematological malignancies. We also further explored the impact of each clinical parameter on GRFS in patients with NHL. Using GRFS as an endpoint, we found that $44.5 \%$ and $36.9 \%$ of patients with advanced NHL survived for 1 and 3 years, respectively, after alloHSCT without any GRFS-related events. Survival outcomes, including GRFS, reached a plateau within 3 years after alloHSCT. The median time to present with a GRFS-related event was 11 months after allo-HSCT, and the majority occurred from 1 month to 3 years. Although it is difficult to directly compare GRFS with other hematological malignancies due to variation in disease-specific characteristics and HSCT approach, our study showed a favorable GRFS rate compared with results previously reported for other hematological malignancies such as acute leukemia or myelodysplastic syndrome $[10,18,19]$, and a similar GRFS rate compared with the previous rate of $30-45 \%$ GRFS at $1-3$ years in patients with lymphoma [20,21].

Dodero et al. [20] reported favorable outcomes (61\% and 50\% 3-year OS and PFS, respectively) with reasonable GRFS (34\% at 3 years) in a relatively homogenous group by treating with the RIC regimen and adding rituximab for GVHD

relapsed aggressive NHL alone receiving allo-HSCT, using 
Fig. 4 Distribution of GRFSdefining events after allo-HSCT in patients with refractory or relapsed NHL. Acute GVHD, chronic GVHD, relapse rate, and death rate differed between 1-year and 3-year after allo-HSCT (A). $\mathrm{BM}$ involvement (b) and disease status pre-HSCT (c) impact GRFS incidence
A

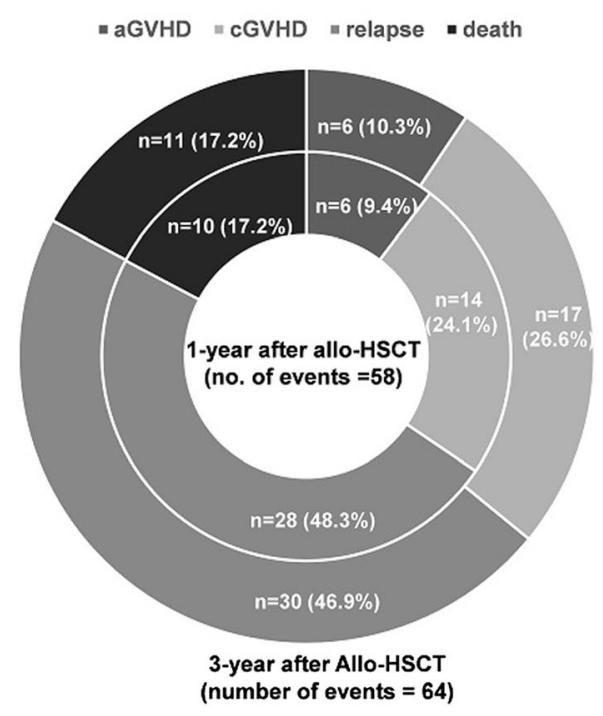

B

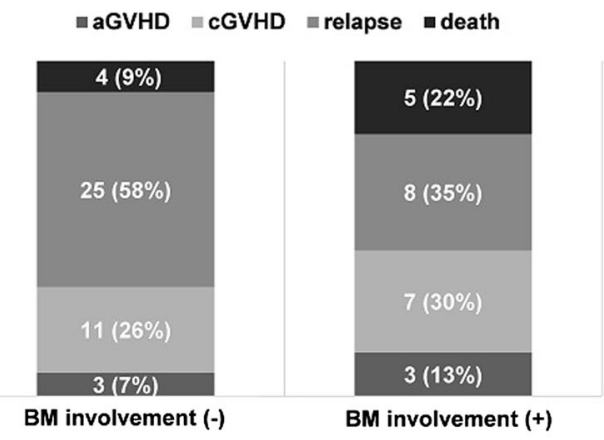

C

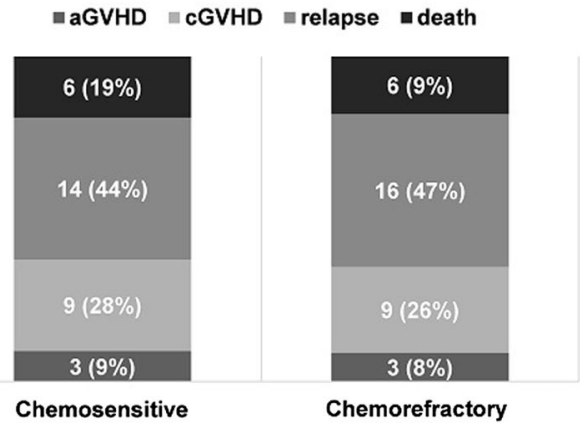

prophylaxis. However, our entire cohort showed similar survival outcomes and GRFS incidence, despite more unfavorable transplant-circumstances such as $\mathrm{SD} / \mathrm{PD}$ status before HSCT or unrelated/haploidentical donors.

When the factors related to an increment in GFRS incidence were analyzed, event incidence of GRFS was higher in patients with more cumulated lines of chemotherapy before allo-HSCT, an involved BM at initial diagnosis or chemorefractory disease status before transplant. However, these were merely fixed biological factors that were determined by initial disease status, and no transplant-associated variables were found. In various hematology malignancies, Holtan et al. [10] suggested that adjust clinical factors, such as BM source or donor type, among the transplant-associated factors. However, our cohort had no adjustable transplantrelated factors including donor type, donor age, conditioning intensity, HLA matching degree, and HCT-CI. To explain these results, we investigated the incidence of each GRFSdefining event. Figure 4 shows that relapse was the most common event type among GRFS-related events at 1 and 3 years after allo-HSCT (Fig. 4a). A relapse event was still the most frequent type after performing individual analyses according to BM involvement or pre-HSCT chemotherapy response status (Fig. 4b, c). In other words, because patients with NHL are inevitably exposed to many chemotherapeutic drugs before allo-HSCT is induced, disease status at the pretransplant period eventually dominates the final survival outcomes after allo-HSCT. Thus, it means that the most crucial factor to improve the GRFS rate of NHL patients is a controlled disease state before allo-HSCT.
According to the previously reported GRFS studies for lymphoma only, the poor GRFS rate was associated with an aggressive pathologic subtype, a prolonged BM involvement, and a related donor stem cell source in B cell lymphoma [20]. Another research for GRFS rate by Gauthier et al. [21] reported similar results in Hodgkin's lymphoma. These studies also identified that haploidentical donors who received ATG had good GRFS compared with mismatched unrelated donors. Based on these results, we also investigated whether the incidence of GRFS was increased by recipients of BM grafts from haploidentical donors $(n=22,21.6 \%)$, MAC regimen $(n=9$, $8.6 \%)$, pathologically aggressive NHL $(n=37,35.6 \%)$, and ATG usage $(n=42,40.4 \%)$. However, our results showed that GRFS incidence was not different from these clinical factors. The incidence of chronic GVHD differs by study, and we used the same RIC regimen for both haploidentical donors and related/unrelated donors; the cumulative incidence of chronic GVHD was relatively high in our center (approximately $10 \%$ vs. $22 \%$ of cumulative incidence of chronic GVHD), and it was expected that this diversity would impact on GRFS.

Then, one way to improve GRFS in patients with refractory or relapsed NHL is to control GVHD events, as a relapse event is not considered by the transplant approach only. We preferentially analyzed the association between the incidence of acute/ chronic GVHD and survival outcomes. The cumulative incidence rates of grades III-IV acute GVHD and systemic therapy-requiring chronic GVHD at 3 years were $5.8 \%$ and $17.6 \%$, respectively (Fig. 1). Acute GVHD did not affect OS or cumulative incidence of relapse (CIR) rates and did not increase NRM further $(p=0.478,0.449$, and 0.754 , respectively; 
Supplementary Figure 2-A, C, and E). In contrast, chronic GVHD improved OS and lowered the CIR rate, but did not increase NRM $(p<0.001,0.021$, and 0.858 , respectively; Supplementary Figure 2-B, D, and F). A possible explanation for this finding is the GVL response; several preclinical and retrospective clinical studies have reported a similar GVL effect in lymphoma [20, 22-24] and in chronic GVHD, but not in acute GVHD, further increasing the GVT effect [25]. Moreover, the low-dose TBI-based nonmyeloablative conditioning regimen relies nearly exclusively on the intensified GVL effect $[26,27]$. Because the method used to calculate GRFS considers chronic GVHD as a fixed negative event, such as relapse or death, and even though chronic GVHD may be fully resolved by short-term treatment, this GRFS method tends to overestimate the impact of chronic GVHD on the outcome of allo-HSCT, particularly in patients with NHL. Solomon et al. [28] and Kawamura et al. [19] presented a dynamic GRFS rate in which GVHD was resolved by short-term treatment in patients with acute leukemia. Therefore, we recalculated the current GRFS, except in patients whose chronic GVHD was fully resolved over a less than 1-month course of systemic immunosuppressants, and analyzed these patients using the revised dynamic GRFS method. As shown in Fig. 5, survival increased over time $(36.9 \%$ vs. $41.9 \%, p=0.045$ for current GRFS vs. revised GRFS at 3 years after allo-HSCT). Thus, we confirmed that chronic GVHD was necessary to achieve the GVL effect in our cohort, and that rapidly controllable chronic GVHD was considered without continuing morbidity or decreased QoL by the ongoing moderate to severe chronic GVHD.

Another way to enhance GRFS by reducing GVHD events is to utilize T cell-replete grafts, which administrated with

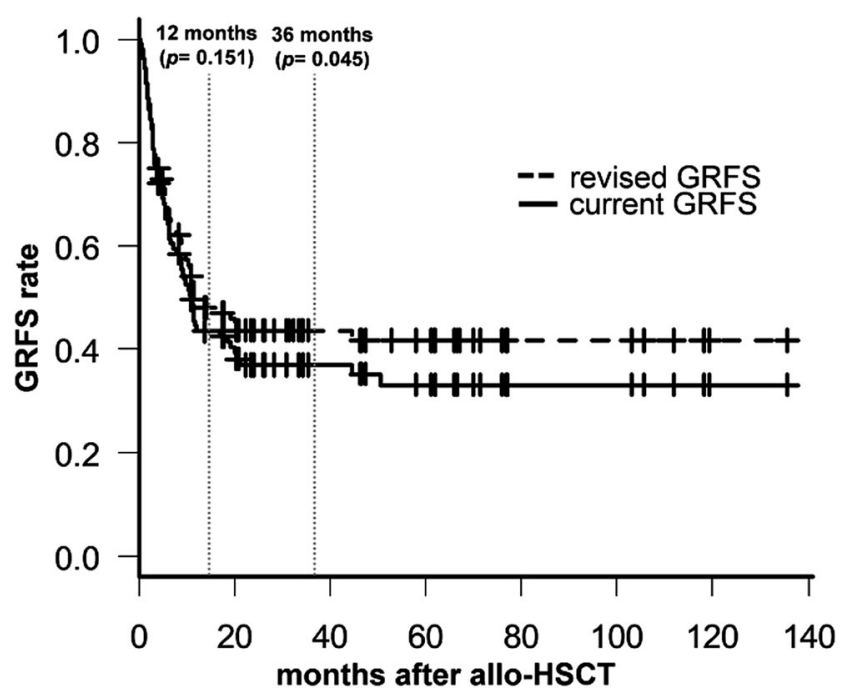

Fig. 5 Comparison of conventional and revised GRFS. The analysis was performed using the revised dynamic GRFS method, except for fully restored chronic GVHD events for short-term systemic immunosuppressive therapy. The results show the advantage of survival compared with the GRFS method intensive immunosuppression using ATG or infusing PT-CY [29]. In this study, we used only ATG as T cell-replete method, which did not affect the incidence of GRFS. This is considered due to heterogeneous subtype and a small number of patients using ATG. However, Kanate et al. [30] reported very promising data related to PT-CY method in haploidentical transplantation for lymphoma: T cell-replete strategy with PT-CY showed that relapse risk, NRM, DFS, and OS were similar with non-PT-CY. However, a risk of grades III-IV acute and chronic GVHD was significantly lower with haploidentical transplantation of PT-CY compared with others. Based on these results, although there were no patients with alloHSCT utilizing PT-CY method in our study, it is strongly possible to predict that GRFS might be improved if using selective PT-CY strategy in haploidentical transplantation.

In conclusion, our results indicate that allo-HSCT for patients with refractory or relapsed NHL alone showed a favorable GRFS rate compared with other previously reported studies for several hematological malignancies, despite the complex pathologic subtypes and variable therapeutic courses of the diseases. We did not identify any modifiable clinical transplant-associated factors that were previously reported in several acute leukemia cohorts. However, BM involvement, pre-HSCT disease status, and exposure lines of chemotherapy before transplantation were related to the GRFS rate, and these results were assumed to be due to the relapse events that were the major consideration in the analysis of GRFSrelated factors. GVHD was shown to be the next most important factor to improve GRFS in patients with relapsed or refractory NHL; it was confirmed that the GVL effect positively influenced survival outcomes, and rapidly resolved chronic GVHD did not result in continued morbidity/ mortality or decreased QoL due to the revised dynamic GRFS. Therefore, considering (and controlling) chronic GVHD as a dynamic event rather than a static one may improve diagnostic accuracy; it is reasonable to assume that resolving chronic GVHD during short-term treatment is a practical way for measuring GRFS in patients with refractory or relapsed NHL only.

Authors' contribution Conception and design: Young-Woo Jeon and Seok-Goo Cho

Development of methodology: Young-Woo Jeon and Seok-Goo Cho

Acquisition of data: Young-Woo Jeon, Seugyun Yoon, Gi June Min, Sung-Soo Park, Silvia Park, Jae-Ho Yoon, Sung-Eun Lee, Byung-Sik Cho, Ki-Seong Eom, Yoo-Jin Kim, Hee-Je Kim, Seok Lee, Chang-Ki Min, Jong Wook Lee, and Seok-Goo Cho

Analysis and interpretation of data (e.g., statistical analysis, biostatistics, computational analysis): Young-Woo Jeon, Seugyun Yoon, Gi June Min, Sung-Soo Park, Silvia Park, Jae-Ho Yoon, Sung-Eun Lee, ByungSik Cho, Ki-Seong Eom, Yoo-Jin Kim, Hee-Je Kim, Seok Lee, Chang-Ki Min, Jong Wook Lee, and Seok-Goo Cho

Writing, review, and revision of the manuscript: Young-Woo Jeon and Seok-Goo Cho

Study supervision: Seok-Goo Cho 
Funding information This work was supported by a National Foundation of Korea (NRF) grant funded by the Korean government (MSIP) (No. NRF-2016R1A2B4007282).

Compliance with ethical standards This study was approved by the Institutional Review Board (IRB) of Seoul St. Mary's Hospital, the Catholic University of Korea in accordance with the Declaration of Helsinki. The informed consent was obtained from all the participants included in this study as per the guidelines of our IRB.

Conflict of interest The authors declare that they have no conflict of interest.

Open Access This article is distributed under the terms of the Creative Commons Attribution 4.0 International License (http:// creativecommons.org/licenses/by/4.0/), which permits unrestricted use, distribution, and reproduction in any medium, provided you give appropriate credit to the original author(s) and the source, provide a link to the Creative Commons license, and indicate if changes were made.

\section{References}

1. Hiddemann W, Kneba M, Dreyling M, Schmitz N, Lengfelder E, Schmits R, Reiser M, Metzner B, Harder H, Hegewisch-Becker S, Fischer T, Kropff M, Reis HE, Freund M, Wormann B, Fuchs R, Planker M, Schimke J, Eimermacher H, Trumper L, Aldaoud A, Parwaresch R, Unterhalt M (2005) Frontline therapy with rituximab added to the combination of cyclophosphamide, doxorubicin, vincristine, and prednisone (CHOP) significantly improves the outcome for patients with advanced-stage follicular lymphoma compared with therapy with CHOP alone: results of a prospective randomized study of the German Low-Grade Lymphoma Study Group. Blood 106(12):3725-3732. https://doi.org/10.1182/blood2005-01-0016

2. Pfreundschuh M, Kuhnt E, Trumper L, Osterborg A, Trneny M, Shepherd L, Gill DS, Walewski J, Pettengell R, Jaeger U, Zinzani PL, Shpilberg O, Kvaloy S, de Nully Brown P, Stahel R, Milpied N, Lopez-Guillermo A, Poeschel V, Grass S, Loeffler M, Murawski N, MabThera International Trial G (2011) CHOP-like chemotherapy with or without rituximab in young patients with good-prognosis diffuse large-B-cell lymphoma: 6-year results of an open-label randomised study of the MabThera International Trial (MInT) Group. Lancet Oncol 12 (11):1013-1022. doi:https://doi.org/10. 1016/S1470-2045(11)70235-2

3. Tsai T, Goodman S, Saez R, Schiller G, Adkins D, Callander N, Wolff S, Freytes CO (1997) Allogeneic bone marrow transplantation in patients who relapse after autologous transplantation. Bone Marrow Transplant 20(10):859-863. https://doi.org/10.1038/sj. bmt.1700989

4. Cheah CY, Fowler NH, Wang ML (2016) Breakthrough therapies in B-cell non-Hodgkin lymphoma. Annals of oncology : official journal of the European society for Med Oncol 27 (5):778-787. doi:https://doi.org/10.1093/annonc/mdw029

5. Epperla N, Hamadani M (2017) Hematopoietic cell transplantation for diffuse large B-cell and follicular lymphoma: current controversies and advances. Hematol Oncol Stem Cell Ther 10(4):277-284. https://doi.org/10.1016/j.hemonc.2017.05.004

6. Corradini P, Tarella C, Olivieri A, Gianni AM, Voena C, Zallio F, Ladetto M, Falda M, Lucesole M, Dodero A, Ciceri F, Benedetti F, Rambaldi A, Sajeva MR, Tresoldi M, Pileri A, Bordignon C, Bregni M (2002) Reduced-intensity conditioning followed by allografting of hematopoietic cells can produce clinical and molecular remissions in patients with poor-risk hematologic malignancies. Blood 99(1):75-82

7. Hamadani M, Saber W, Ahn KW, Carreras J, Cairo MS, Fenske TS, Gale RP, Gibson J, Hale GA, Hari PN, Hsu JW, Inwards DJ, Kamble RT, Klein A, Maharaj D, Marks DI, Rizzieri DA, Savani BN, Schouten HC, Waller EK, Wirk B, Lazarus HM (2013) Allogeneic hematopoietic cell transplantation for chemotherapyunresponsive mantle cell lymphoma: a cohort analysis from the center for international blood and marrow transplant research. Biol Blood Marrow Transplant 19(4):625-631. https://doi.org/10. 1016/j.bbmt.2013.01.009

8. Fenske TS, Hamadani M, Cohen JB, Costa LJ, Kahl BS, Evens AM, Hamlin PA, Lazarus HM, Petersdorf E, Bredeson C (2016) Allogeneic hematopoietic cell transplantation as curative therapy for patients with non-Hodgkin lymphoma: increasingly successful application to older patients. Biol Blood Marrow Transplant 22(9): 1543-1551. https://doi.org/10.1016/j.bbmt.2016.04.019

9. Gyurkocza B, Sandmaier BM (2014) Conditioning regimens for hematopoietic cell transplantation: one size does not fit all. Blood 124(3):344-353. https://doi.org/10.1182/blood-2014-02-514778

10. Holtan SG, DeFor TE, Lazaryan A, Bejanyan N, Arora M, Brunstein CG, Blazar BR, MacMillan ML, Weisdorf DJ (2015) Composite end point of graft-versus-host disease-free, relapsefree survival after allogeneic hematopoietic cell transplantation. Blood 125(8):1333-1338. https://doi.org/10.1182/blood-2014-10609032

11. Pasquini MC, Logan B, Jones RJ, Alousi AM, Appelbaum FR, Bolanos-Meade J, Flowers MED, Giralt S, Horowitz MM, Jacobsohn D, Koreth J, Levine JE, Luznik L, Maziarz R, Mendizabal A, Pavletic S, Perales MA, Porter D, Reshef R, Weisdorf D, Antin JH (2018) Blood and marrow transplant clinical trials network report on the development of novel endpoints and selection of promising approaches for graft-versus-host disease prevention trials. Biol Blood Marrow Transplant 24(6):1274-1280. https://doi.org/10.1016/j.bbmt.2018.01.002

12. Sabattini E, Bacci F, Sagramoso C, Pileri SA (2010) WHO classification of tumours of haematopoietic and lymphoid tissues in 2008: an overview. Pathologica 102(3):83-87

13. Weisdorf D, Spellman S, Haagenson M, Horowitz M, Lee S, Anasetti C, Setterholm M, Drexler R, Maiers M, King R, Confer D, Klein J (2008) Classification of HLA-matching for retrospective analysis of unrelated donor transplantation: revised definitions to predict survival. Biol Blood Marrow Transplant 14(7):748-758. https://doi.org/10.1016/j.bbmt.2008.04.003

14. Gratwohl A (2012) The EBMT risk score. Bone Marrow Transplant 47(6):749-756. https://doi.org/10.1038/bmt.2011.110

15. Thomas ED, Storb R, Clift RA, Fefer A, Johnson L, Neiman PE, Lerner KG, Glucksberg H, Buckner CD (1975) Bone-marrow transplantation (second of two parts). N Engl J Med 292(17):895902. https://doi.org/10.1056/NEJM197504242921706

16. Jagasia MH, Greinix HT, Arora M, Williams KM, Wolff D, Cowen EW, Palmer J, Weisdorf D, Treister NS, Cheng GS, Kerr H, Stratton $\mathrm{P}$, Duarte RF, McDonald GB, Inamoto Y, Vigorito A, Arai S, Datiles MB, Jacobsohn D, Heller T, Kitko CL, Mitchell SA, Martin PJ, Shulman H, Wu RS, Cutler CS, Vogelsang GB, Lee SJ, Pavletic SZ, Flowers ME (2015) National Institutes of Health consensus development project on criteria for clinical trials in chronic graft-versus-host disease: I. The 2014 Diagnosis and Staging Working Group report. Biol Blood Marrow Transplant 21(3):389-401 e381. https://doi.org/10.1016/j.bbmt.2014.12.001

17. Kanda Y (2013) Investigation of the freely available easy-to-use software 'EZR' for medical statistics. Bone Marrow Transplant 48(3):452-458. https://doi.org/10.1038/bmt.2012.244

18. Ruggeri A, Labopin M, Ciceri F, Mohty M, Nagler A (2016) Definition of GvHD-free, relapse-free survival for registry-based studies: an ALWP-EBMT analysis on patients with AML in 
remission. Bone Marrow Transplant 51(4):610-611. https://doi. org/10.1038/bmt.2015.305

19. Kawamura K, Nakasone H, Kurosawa S, Yoshimura K, Misaki Y, Gomyo A, Hayakawa J, Tamaki M, Akahoshi Y, Kusuda M, Kameda K, Wada H, Ishihara Y, Sato M, Terasako-Saito K, Kikuchi M, Kimura SI, Tanihara A, Kako S, Kanamori H, Mori T, Takahashi S, Taniguchi S, Atsuta Y, Kanda Y (2018) Refractory graft-versus-host disease-free, relapse-free survival as an accurate and easy-to-calculate endpoint to assess the long-term transplant success. Biol Blood Marrow Transplant 24:1521-1526. https:// doi.org/10.1016/j.bbmt.2018.02.004

20. Dodero A, Patriarca F, Milone G, Sarina B, Miceli R, Iori A, Barretta F, Terruzzi E, Mussetti A, Pini M, Bosi A, Dominietto A, Cascavilla N, Onida F, Narni F, Farina L, Rambaldi A, Corradini P (2017) Allogeneic stem cell transplantation for relapsed/refractory B cell lymphomas: results of a multicenter phase II prospective trial including rituximab in the reduced-intensity conditioning regimen. Biol Blood Marrow Transplant 23(7):1102-1109. https://doi.org/ 10.1016/j.bbmt.2017.03.031

21. Gauthier J, Castagna L, Garnier F, Guillaume T, Socie G, Maury S, Maillard N, Tabrizi R, Marchand T, Malfuson J, Gac A, Gyan E, Mercier M, Beguin Y, Delage J, Turlure P, Marcais A, Nguyen S, Dulery R, Bay J, Huynh A, Daguindau E, Cornillon J, Regny C, Michallet M, Peffault de Latour R, Yakoub-Agha I, Blaise D (2017) Reduced-intensity and non-myeloablative allogeneic stem cell transplantation from alternative HLA-mismatched donors for Hodgkin lymphoma: a study by the French Society of Bone Marrow Transplantation and Cellular Therapy. Bone Marrow Transplant 52:689-696. https://doi.org/10.1038/bmt.2016.349

22. William BM, Wang T, Haagenson MD, Fleischhauer K, Verneris M, Hsu KC, de Lima MJ, Fernandez-Vina M, Spellman SR, Lee SJ, Hill BT (2018) Impact of HLA alleles on outcomes of allogeneic transplantation for B cell non-Hodgkin lymphomas: a Center for International Blood and Marrow Transplant Research analysis. Biol Blood Marrow Transplant 24(4):827-831. https://doi.org/10.1016/ j.bbmt.2017.11.003

23. Cudillo L, Cerretti R, Picardi A, Mariotti B, De Angelis G, Cantonetti M, Postorino M, Ceresoli E, De Santis G, Nasso D, Pisani F, Scala E, Di Piazza F, Lanti A, William Arcese for the Rome transplant N (2018) Allogeneic hematopoietic stem cell transplantation in primary cutaneous $\mathrm{T}$ cell lymphoma. Ann Hematol 97 (6):1041-1048. https://doi.org/10.1007/s00277-0183275-z, 2018

24. Shiratori S, Yasumoto A, Tanaka J, Shigematsu A, Yamamoto S, Nishio M, Hashino S, Morita R, Takahata M, Onozawa M, Kahata K, Kondo T, Ota S, Wakasa K, Sugita J, Koike T, Asaka M, Kasai M, Imamura M (2008) A retrospective analysis of allogeneic hematopoietic stem cell transplantation for adult $\mathrm{T}$ cell leukemia/ lymphoma (ATL): clinical impact of graft-versus-leukemia/lymphoma effect. Biol Blood Marrow Transplant 14(7):817-823. https://doi.org/10.1016/j.bbmt.2008.04.014
25. Storb R, Gyurkocza B, Storer BE, Sorror ML, Blume K, Niederwieser D, Chauncey TR, Pulsipher MA, Petersen FB, Sahebi F, Agura ED, Hari P, Bruno B, McSweeney PA, Maris MB, Maziarz RT, Langston AA, Bethge W, Vindelov L, Franke GN, Laport GG, Yeager AM, Hubel K, Deeg HJ, Georges GE, Flowers ME, Martin PJ, Mielcarek M, Woolfrey AE, Maloney DG, Sandmaier BM (2013) Graft-versus-host disease and graftversus-tumor effects after allogeneic hematopoietic cell transplantation. J Clin Oncol 31(12):1530-1538. https://doi.org/10.1200/ JCO.2012.45.0247

26. Baron F, Labopin M, Ruggeri A, Cornelissen JJ, Meijer E, Sengeloev H, Niederwieser D, de Groot MR, Schouten HC, Milpied NJ, Blaise D, Savani B, Gluckman E, Mohty M, Nagler A (2018) Impact of donor type in patients with AML given allogeneic hematopoietic cell transplantation after low-dose TBI based regimen. Clin Cancer Res 24:2794-2803. https://doi.org/10.1158/ 1078-0432.CCR-17-3622

27. Gyurkocza B, Storb R, Storer BE, Chauncey TR, Lange T, Shizuru JA, Langston AA, Pulsipher MA, Bredeson CN, Maziarz RT, Bruno B, Petersen FB, Maris MB, Agura E, Yeager A, Bethge W, Sahebi F, Appelbaum FR, Maloney DG, Sandmaier BM (2010) Nonmyeloablative allogeneic hematopoietic cell transplantation in patients with acute myeloid leukemia. J Clin Oncol 28(17):28592867. https://doi.org/10.1200/JCO.2009.27.1460

28. Solomon SR, Sizemore C, Zhang X, Ridgeway M, Solh M, Morris LE, Holland HK, Bashey A (2017) Current graft-versus-host disease-free, relapse-free survival: a dynamic endpoint to better define efficacy after allogenic transplant. Biol Blood Marrow Transplant 23(7):1208-1214. https://doi.org/10.1016/j.bbmt.2017.02.022

29. Solh M, Zhang X, Connor K, Brown S, Solomon SR, Morris LE, Holland HK, Bashey A (2016) Factors predicting graft-versus-host disease-free, relapse-free survival after allogeneic hematopoietic cell transplantation: multivariable analysis from a single center. Biol Blood Marrow Transplant 22(8):1403-1409. https://doi.org/ 10.1016/j.bbmt.2016.04.006

30. Kanate AS, Mussetti A, Kharfan-Dabaja MA, Ahn KW, DiGilio A, Beitinjaneh A, Chhabra S, Fenske TS, Freytes C, Gale RP, Ganguly S, Hertzberg M, Klyuchnikov E, Lazarus HM, Olsson R, Perales MA, Rezvani A, Riches M, Saad A, Slavin S, Smith SM, Sureda A, Yared J, Ciurea S, Armand P, Salit R, BolanosMeade J, Hamadani M (2016) Reduced-intensity transplantation for lymphomas using haploidentical related donors vs HLA-matched unrelated donors. Blood 127(7):938-947. https://doi.org/10.1182/blood-2015-09-671834

Publisher's note Springer Nature remains neutral with regard to jurisdictional claims in published maps and institutional affiliations. 